\title{
Mortality of preterm neonates and its predictors in the Northwest part of Ethiopia: A retrospective cohort study
}

Aklilu Endalamaw Sinshaw ( $\square$ yaklilu12@gmail.com )

Bahir Dar University https://orcid.org/0000-0002-9121-6549

Biniam Minuye

Debre Tabor University

Bezatu Mengistie

Haramaya University

Abebaw Yeshambel

Debre Tabor University

Nega Assefa

Haramaya University

Research article

Keywords: Preterm, Neonate, Mortality, Ethiopia

Posted Date: July 2nd, 2019

DOI: https://doi.org/10.21203/rs.2.10832/v1

License: (c) (i) This work is licensed under a Creative Commons Attribution 4.0 International License.

Read Full License 


\section{Abstract}

Abstract Background: Preterm birth is highly reported in some countries and disparities on survival rates of preterm neonate are escalating across countries. Providing adequate medical care during pregnancy and childbirth has been endorsed. However, neonatal mortality is continuing to be one of the sustainable development goals. To achieve this aim, data from the different geographical area is suggested. Objective: This study was aimed to assess mortality of preterm neonates and its predictors in the Northwest part of Ethiopia. Methods: Institution based retrospective cohort study was conducted among 535 preterm neonates. Data was entered into EPi-data 4.2.0.0 and transferred to STATA version 14 statistical software for analysis. Kaplan-Meier survival analysis and Log-rank test were used to see statistical differences between categories of variables. Cox proportional hazard model was used to identify independent predictors of preterm neonatal mortality. The proportional assumption test had been checked using the Schoenfeld residual test. Variables with $p$-value $\leq 0.05$ were considered as predictors of preterm neonatal mortality. Results: In this study, $31.2 \%(95 \% \mathrm{Cl}: 27.3,35.1)$ of preterm neonate were died. Preterm neonates with a gestational age of less than 32 weeks (AHR=1.74; 95\% Cl: 1.24, 2.46), being male sex (AHR=1.38; 95\%Cl: 1.01, 1.90), born from preeclampsia/ eclampsia mothers (AHR=1.95; 95\% Cl: $1.13,3.36)$, being extremely very low birth weight (AHR=2.94; 95\% Cl: 1.05, 8.24), diagnosed with respiratory distress syndrome $(\mathrm{AHR}=1.70 ; 95 \% \mathrm{Cl}: 1.20,2.41)$ were predictors of preterm death. Conclusion and Recommendations: Preterm neonatal mortality found to be high. Four neonatal and one maternalrelated variable were recognized predictors of mortality in preterm neonates. The study suggests preventing and controlling preeclampsia/ eclampsia, especial care for neonates born with very low birth weight, born before 32 weeks of gestation, and diagnosed with respiratory distress syndrome are imperative. Keywords: Preterm, Neonate, Mortality, Ethiopia

\section{Background}

Preterm neonate is babies born alive before 37 completed weeks of gestation (1). It is one of the main problems and inconsistencies on mortality of preterm neonate are escalating across countries (2). Globally, 15 million preterm neonates are born each year. Of which, more than $60 \%$ of preterm neonates are found in Africa and South Asia $(3,4)$.

An estimated three-quarter of preterm babies could survive by receiving inexpensive care (5). Subsequently, to prevent mortality of preterm neonate, World Health Organization's (WHO) proposed interventions to decrease mortality of preterm neonate. For instance, antenatal corticosteroids, magnesium sulfate, and antibiotic prophylaxis for mothers and Kangaroo mother care, plastic wraps, continuous positive airway pressure therapy, surfactant, and oxygen therapy for neonates are some of them (6).

Despite these interventions, preterm birth is one of the common causes of death in different countries (7). At different time, mortality of preterm neonates reported as $69 \%$ in Cameron (8), $52 \%$ in East Africa (9), and $21.8 \%$ to $34 \%$ in Ethiopia (10-13). 
The causes of mortality in preterm neonates are multi-factorial and affected by biological, genetic, social, psychological, geographic, and demographic characteristics of the population. Based on the previous studies, very extreme preterm, maternal medical problems, male sex neonate, neonate diagnosed for hypothermia and hyaline membrane disease, and babies born with short birth interval have excessive mortality compared to their counterparts (14-19) were determinants of mortality in preterm neonates. Besides, clinical, behavioral, and health system-related interventions have a potential impact on mortality of preterm neonates (20).

To achieve sustainable development goal (SDG) in reducing child mortality, investigated data from the different geographical area of Ethiopia is necessary. Afterward, recognize the burden of preterm neonatal mortality is essential. Thus, the current study was intended to fill the information gap on preterm neonatal mortality and its predictors in the Northwest part of Ethiopia.

\section{Methods And Materials}

\section{Study, design, period, setting, and population}

The study was conducted through retrospective cohort study from January 22-February 5/2018 at Debretabor General Hospital, Northwest Ethiopia. Debretabor town is found $666 \mathrm{~km}$ far from Addis Ababa and $105 \mathrm{~km}$ from Bahirdar, Ethiopia. Debretabor General Hospital is the largest hospital in South Gondar Zone which was established in 1931. The hospital has been provided health care service for more than 2.4 million populations in its catchment area in the Northwest part of Ethiopia. It has a neonatal Intensive Care Unit (NICU) with a total of 21 neonatal beds and approximately 1,159 neonatal admissions per year. Most of the admissions were associated with premature delivery (21). All preterm neonates ( $<37$ weeks of gestational age) in Debretabor General Hospital, Northwest Ethiopia were the study population. Gestational age was assessed using LNMP (last normal menstruation period) or ultrasound whenever mothers couldn't remember LNMP.

\section{Sample size determination and sampling procedure}

The sample size was determined using Open EPi Info 7 Statcalc through double population proportion formula with the assumptions of $95 \% \mathrm{Cl}, 5 \%$ margin of error, $80 \%$ power and exposed to unexposed ratio 1:1 by double population proportion formula by considering perinatal asphyxia (PNA), weight at birth, and sex of neonate (22-24)from previous studies, the estimated sample size was 86,114 , and 524 respectively. However, the number 524 is selected because of its largest sample size. By adding $10 \%$ nonresponse rate, the final sample size was 576. A study participant selection process illustrated (Figure 1).

\section{Data collection methods}

Data were collected based on a structured data abstraction sheet from preterm neonate medical records. The abstraction sheet includes maternal socio-demographic, obstetric and gynecological, prenatal, intranatal, and neonatal-related variables with considering mortality of preterm neonate as an outcome 
variable. The data was collected by six BSc nurses and with the involvement of two MSc nurse supervisors. Completeness of each recorded tool was checked soon after collecting the data.

\section{Operational definitions}

The death of a preterm neonate time variable (admission to death time) was recorded. Besides, survival time was measured considered the follow-up time (from date of admission to the occurrence of a death). Preterm neonates referred to another institutions, discharged, and alive at the end of the follow-up period were considered censored.

\section{Data quality control}

A pretest was done on $5 \%$ of the sample size. Training was given for data collectors and supervisors about data collection tools and procedure. Supervisors closely monitored data collection process. The principal investigator and supervisors checked the completeness of each abstraction sheet on a daily base. Two data clerks entered data and consistency of the entered data was cross-checked.

\section{Statistical analysis}

Data were entered, coded, cleaned and checked by Epi Data version 4.2.0.0 and analysis was done using STATA Version 14 statistical software. Descriptive statistics of included variables had been presented by tables and pie chart. Kaplan Meier curves were used to estimate survival time and to depict the pattern of death. The log-rank test was used to look at statistical differences between categories of variables. Bivariable analysis of the individual variables with preterm neonatal survival mortality was carried out to include in the Cox-proportional hazard model. P-value $<0.2$ in the log-rank test was entered into multivariable analysis. Then, the proportional assumption test had been checked using the Schoenfeld residual test. The assumption met with a $p$-value in the global test $(P=0.35)$. Adjusted Hazard ratio (AHR) with $95 \%$ confidence interval $(\mathrm{Cl})$ had been generated from multivariable analysis and a statistical significance had been accepted at $p$-value $\leq 0.05$.

\section{Ethical considerations}

Ethical clearance was obtained from Haramaya University, College of Health and Medical Sciences, Institutional Health Research Ethics Review Committee. Then, official letter had been written to Debretabor General Hospital for permission and support. The neonate's name and medical record identification information had not been collected and confidentiality was maintained. All data collected from the chart were kept strictly confidential and used only for the study purpose.

\section{Results}

\section{Socio-demographic characteristics of the mother and neonates}

A total of six hundred fourteen preterm neonates were admitted during the study period. Of these, five hundred eighty-nine charts were reviewed and only five hundred thirty-five study participants were involved with a response rate of $90.8 \%$. The mean $( \pm S D)$ age of the mother was $27.56( \pm 6.54)$ years. Fort- 
seven percent $(47.3 \%)$ of mothers were in the age group of $20-29$ years. The majority $(72.71 \%)$ of them were from the rural area. Most (92.5\%) of the neonates were admitted within the first day of birth. More than half (51.6\%) were males (Table 1).

\section{Obstetrics/gynecological characteristics}

Seventy-seven percent (77.1\%) of mothers had ante-natal care (ANC) follow-up. Out of which, $15.1 \%$ had four and above ANC contact and $34.9 \%$ of mothers had encountered maternal complication during the current pregnancy, labor and delivery, such as pregnancy induced hypertension $(\mathrm{PIH}) /$ preeclampsia/eclampsia, premature rupture of membrane (PROM), antepartum hemorrhage (APH), and chorioamnionitis. Majority (60.2\%) of preterm neonate was born at Debretabor General Hospital (Table 2).

\section{Neonatal characteristics}

Sixty-nine percent $(69.2 \%)$ of neonates were born with the gestational age of greater than or equal to thirty-two weeks. Sixty-eight percent $(67.8 \%)$ of preterm neonate were low birth weight and $90.1 \%$ were hypothermic during admission time. From all neonates, $86.2 \%$ of preterm neonates had neonatal complications during admissions, such as sepsis, respiratory distress syndrome (RDS), PNA, and meconium aspiration syndrome (MAS) (Table 3).

\section{Kaplan-Meier survival curve}

Five hundred thirty-five participants were followed for a different time ranging from one day to 40 days, which provided 4985.86 days total time at risk. The median survival time was 27 days. Preterm neonatal survival probability by the end of follow-up was $0.50(95 \% \mathrm{Cl}: 0.42,0.58)$. The graph shows the proportion of neonates who survived during the follow-up time (Figure 2). Of all study participants, $31.2 \%$ (95\% Cl: $27.3,35.1)$ preterm neonates were died; $326(60.9 \%)$ improved, $7(1.3 \%)$ referred to other institution for further management, absconded 1 (0.2\%), and left against medical advice were 34 (6.4\%).

\section{Predictors of mortality of preterm neonate}

In multivariable Cox regression analysis, gestational age $<32$ weeks, male sex, mothers diagnosed with preeclampsia/eclampsia, very extreme birth weight, and neonatal respiratory distress syndrome were found to be significant predictors.

Preterm neonates who were born with a gestational age of less than 32 weeks of gestation had 1.74 $(95 \% \mathrm{Cl}: 1.24,2.46)$ times more hazard of death than neonate born with a gestational age of greater than or equal to 32 weeks of gestation. Preterm neonates born from preeclampsia/eclampsia mother were 1.95 (95\% Cl: $1.13,3.36)$ times more hazard of death than preterm neonate born from nonpreeclampsia/eclampsia mothers. Male preterm neonates were 1.38 (95\%Cl: 1.01, 1.90) times more hazard of death than female preterm neonates. Extremely low birth weight preterm neonates were 2.94 $(95 \% \mathrm{Cl}: 1.05,8.24)$ times more hazard of death than normal birth weight preterm neonates. A preterm 
neonate who had respiratory distress syndrome was $1.70(95 \% \mathrm{Cl}: 1.20,2.41)$ times more hazard of death as compared to their counter parts (Table 4).

\section{Discussion}

Preterm mortality is the major causes of neonatal mortality in low and middle-income countries (25). Similarly, this study revealed that the proportion of preterm mortality was found to be $31.2 \%(95 \% \mathrm{Cl}$ : 27.3, 35.1). This finding is comparable with studies conducted in Addis Ababa, Ethiopia $30.7 \%$ (23), Jimma Ethiopia 34.9\% (22) and Nigeria 27.7\% (26). Though low cost interventions are critical to reduce neonatal mortality, the problem is still high as evidenced from these studies. This similarity might be due to in developing world, the services provided for maternal and neonatal health are not sufficient. Social exclusion, caste, maternal literacy, lack of basic prenatal, natal, and postnatal care might be the problem in developing countries.

On the other hand, the finding of the current study is higher than studies conducted in Iran $9.1 \%$ (27) and China $8.8 \%$ (28). This difference might be due to the high quality of service provided in Iran and China. Studies in Iran and China were conducted in the hospital with level III NICU while this study was conducted in General hospital with level II NICU. Moreover, the low proportion of mortality Iran and China is due to infants born preterm have received improved care during pre-pregnancy, antenatal, intrapartum, and post-natal periods $(29,30)$. Besides, preventive and control measures of infections in developed countries are strictly implemented.

Predictors of the high mortality of preterm neonate are also identified in the current study. Accordingly, gestational age of less than 32 weeks, male neonate, neonate born from preeclampsia/eclampsia women, very extreme low birth weight neonate, and neonate with respiratory distress syndrome were identified predictors of mortality of preterm neonate.

This study showed that preterm neonates who were born with a gestational age of less than 32 weeks of gestation were more hazard of death than neonate born with a gestational age of greater than or equal to 32 weeks of gestation. This finding was consistent with studies conducted in Jimma, Ethiopia (22) and Nigeria (26). The possible explanation could be the effect of gestational age was partially explained by the heterogeneity of mechanisms leading to physiological immaturity and biological determinants of preterm birth acting through gestational age. Moreover, placental ischemia and other hypoxia exacerbated the effect of gestational age to poor outcomes $(31,32)$. The frequency of preterm neonatal morbidities decreased above 32 weeks of gestation and each additional week for gestation has survival benefit while reducing the length of hospitalization (33).

Preterm neonates born from preeclampsia/eclampsia mother were more hazard of death than preterm neonate born from non-preeclampsia/eclampsia mothers. This finding is agreeing with studies conducted in Netherland (34) and Australia (35). The reason could be preeclampsia/eclampsia increases the rate of born with small for gestational age and further it increases neonatal complications (34). 
Furthermore, preeclampsia could impair fetal growth through reducing uteroplacental perfusion (36), which leads to neonatal morbidity (37) and neonatal mortality as a result. Induction of non-spontaneous labour, high oxidative stress, and free radicals from preeclampsia/eclampsia mother might lead to neonatal mortality.

Male preterm neonates were more hazard of death than female preterm neonates. This finding approved results from previous study done in Ethiopia, Tanzania, Pennsylvania, Switzerland, England, California, China $(23,28,35,38-40)$. This could high preterm birth, operative delivery, neonatal death, congenital anomaly, increased rate of respiratory morbidity $(41,42)$, such as respiratory distress syndrome, bronchopulmonary dysplasia, intra-ventricular hemorrhage, and retinopathy of prematurity $(43,44)$ are highly observed in male preterm neonates.

Extremely low birth weight preterm neonates were more hazard of death than normal birth weight preterm neonates. This study is consistent with studies conducted in South Africa, Malawi, and China $(28,45,46)$. This could be due to extremely low birth weight babies are more likely to born prematurely and suffer from infections (47). In extremely low birth weight neonate, immaturity of physiological and anatomical structures, principally lung deficient in surfactant, lack of subcutaneous tissue, large surface area to body mass ratio and fragile capillaries in their brain may lead to have more medical problems.

In the present study, preterm neonates who had respiratory distress syndrome were more hazard of death than preterm neonates without respiratory distress syndrome. This study is consistent with the study conducted in Gondar and Jimma Ethiopia $(22,48)$. Tracheoesophageal fistula, bronchopulmonary sequestration, and bronchogenetic cysts might be the underlined causes of respiratory distress syndrome. Failure to diagnose and treat these underlined causes of respiratory distress syndrome could leads to short-and long-term complications including death of neonates.

The finding of the current study will enable health policy and/or decision makers to establish or strengthening already established programs that aimed at reducing neonatal morbidity and mortality. Though a very limitation of resources observed in the study settings, many of contributing factors for neonatal mortality can be preventable. Priority and special attention has to be given for the identified independent predictors to prevent neonatal mortality.

\section{Limitation of the study}

Since the study was retrospective follow-up and depends on medical records not designed for research which is prone to data incompleteness. Mode of labour (spontaneous or induced) and level of preeclampsia were not recorded. The time-covariate variables were not handled because the data were collected at baseline.

\section{Conclusions}

The preterm neonatal mortality is high. Gestational age, sex of neonates, preeclampsia /eclampsia, birth weight, and respiratory distress syndrome were important predictors of mortality in preterm neonates. 
Therefore, a great focus should be given towards addressing universal antenatal care and health institution delivery with much emphasis on the preterm neonate. In addition, managing maternal complications, low birth weight, prematurity and ensuring a continuum of care to decrease mortality of preterm neonates.

\section{List Of Abbreviations:}

AHR: Adjusted Hazard Ratio; ANC: Antenatal Care; APH: Antepartum Hemorrhage; Cl: Confidence Interval; CHR: Crude Hazard Ratio; NICU: Neonatal Intensive Care Unit; PROM: premature rupture of membrane; PNA: perinatal asphyxia; RDS: Respiratory Distress Syndrome; SDG: Sustainable development goal; WHO: World Health Organization

\section{Declarations}

Ethical approval and consent to participate: Ethical clearance was obtained from Haramaya University, College of Health and Medical Sciences, Institutional Health Research Ethics Review Committee.

Consent to publication: Not applicable

Availability of data and materials: Data will be available upon request from the corresponding author.

Competing interests: The authors declare that they have no competing interests.

Funding: Not applicable

Authors' Contribution: BM worked on designing the study, training the data collectors, supervising the data collectors, interpreting the result, preparing the manuscript. BM1, BM, NA, AY, and AE analyzed and interpreted the result and wrote the manuscript. All authors involved starting from design, data interpretation, to critically review the manuscript.

Acknowledgment: The authors acknowledged the Debretabor University for its financial support, Debretabor General Hospital, and data collectors.

\section{Reference}

1. WHO. Preterm birth.http://www.who.int/mediacentre/factsheets/fs363/en/.accesed date september 30/2017. 2016.

2. Numerato D, Fattore G, Tediosi F, Zanini R, Peltola M, Banks $H$, et al. Mortality and length of stay of very low birth weight and very preterm infants: a EuroHOPE study. PLoS One. 2015;10(6):e0131685.

3. Kliegman RM, Nelson WE. Nelson textbook of pediatrics. Philadelphia: Elsevier; 2016.

4. Rennie JM, Roberton NRC. Rennie and Roberton's textbook of neonatology. Edinburgh: Churchill Livingstone/Elsevier; 2012. 
5. CDC. Preterm Birth.https://www.cdc.gov/features/prematurebirth/index.html.accessed date october 10/2017. 2017.

6. WHO. WHO recommendations on interventions to improve preterm birth outcomes.http://www.who.int/reproductivehealth/publications/maternal_perinatal_health/preterm-birthguideline/en/.accessed on october $2 / 2017$

2015.

7. Liu L, Oza S, Hogan D, Perin J, Rudan I, Lawn JE, et al. Global, regional, and national causes of child mortality in 2000-13, with projections to inform post-2015 priorities: an updated systematic analysis. The Lancet. 2015;385(9966):430-40.

8. Ndombo PK, Ekei QM, Tochie JN, Temgoua MN, Angong FTE, Ntock FN, et al. A cohort analysis of neonatal hospital mortality rate and predictors of neonatal mortality in a sub-urban hospital of Cameroon. Italian journal of pediatrics. 2017;43(1):52.

9. Marchant T, Willey B, Katz J, Clarke S, Kariuki S, Ter Kuile F, et al. Neonatal mortality risk associated with preterm birth in East Africa, adjusted by weight for gestational age: individual participant level metaanalysis. PLoS medicine. 2012;9(8):e1001292.

10. CSA and ICF. Ethiopia Demographic and Health Survey 2016.https://dhsprogram.com/pubs/pdf/FR328/FR328.pdf.accessed on July/2017. 2016.

11. WHO. MCEE estimates for child causes of death, 20002015.www.who.int/healthinfo/global_burden_disease/estimates/en/index3.htm. 2016.

12. Mekonnen Y, Tensou B, Telake DS, Degefie T, Bekele A. Neonatal mortality in Ethiopia: trends and determinants. BMC public health. 2013;13(1):483.

13. Mengesha, Gebrekirstos H, Sahle BW. Cause of neonatal deaths in Northern Ethiopia: a prospective cohort study. BMC public health. 2017;17(1):62.

14. Koullali B, Oudijk MA, Nijman TA, Mol BW, Pajkrt E. Risk assessment and management to prevent preterm birth. Seminars in fetal \&amp; neonatal medicine. 2016;21(2):80-8.

15. Abdel Razeq NM, Khader YS, Batieha AM. The incidence, risk factors, and mortality of preterm neonates: A prospective study from Jordan (2012-2013). Turkish journal of obstetrics and gynecology. 2017;14(1):28-36.

16. Whiteman VE, August EM, Mogos M, Naik E, Garba M, Sanchez E, et al. Preterm birth in the first pregnancy and risk of neonatal death in the second pregnancy: a propensity score-weighted matching approach. Journal of obstetrics and gynaecology : the journal of the Institute of Obstetrics and Gynaecology. 2015;35(1):30-6. 
17. Wagijo MA, Sheikh A, Duijts L, Been JV. Reducing tobacco smoking and smoke exposure to prevent preterm birth and its complications. Paediatric respiratory reviews. 2017;22:3-10.

18. Lean SC, Derricott $H$, Jones RL, Heazell AE. Advanced maternal age and adverse pregnancy outcomes: A systematic review and meta-analysis. PLoS One. 2017;12(10):e0186287.

19. Parker MG, Ouyang F, Pearson C, Gillman MW, Belfort MB, Hong X, et al. Prepregnancy body mass index and risk of preterm birth: association heterogeneity by preterm subgroups. BMC pregnancy and childbirth. 2014;14(1):153.

20. Requejo J, Bryce J, Victora C, Deixel A. Accountability for maternal newborn and child survival: The 2013 update. 2013.

21. DTH. Debretabor General Hospital Report 2009 EC. 2017.

22. Wesenu M, Kulkarni S, Tilahun T. Modeling Determinants of Time-To-Death in Premature Infants Admitted to Neonatal Intensive Care Unit in Jimma University Specialized Hospital. Annals of Data Science. 2017:1-21.

23. Merertu M, Bogale Worku M, Yonas Regassa M, Amha Mekasha M. Survial Of Preterm Infants Admitted To Tikur Anbessa Hospital Nicu, Addis Ababa. ETHIOPIAN JOURNAL OF PEDIATRICS AND CHILD HEALTH. 2014; Volume X, Number 10:68.

24. Basiri B, Ashari FE, Shokouhi M, Sabzehei MK. Neonatal Mortality and its Main Determinants in Premature Infants Hospitalized in Neonatal Intensive Care Unit in Fatemieh Hospital, Hamadan, Iran. Journal of Comprehensive Pediatrics. 2015;6(3).

25. WHO WB, UN Department of Economic and Social Affairs, UN Children's Fund. Levels \& Trends in Child Mortality: Report 2017.https://reliefweb.int/report/world/levels-trends-child-mortality-report2017.accessed date on december 4 2017. 2017.

26. Bako B, Idrisa A, Garba M, Pius S, Obetta H. Determinants of neonatal survival following preterm delivery at the University of Maiduguri Teaching Hospital, Maiduguri, Nigeria. Tropical Journal of Obstetrics and Gynaecology. 2017;34(1):39.

27. Haghighi L, Nojomi M, Mohabbatian B, Najmi Z. Survival predictors of preterm neonates: Hospital based study in Iran (2010-2011). Iran J Reprod Med. 2013;11(12):957-64.

28. Kong X, Xu F, Wu R, Wu H, Ju R, Zhao X, et al. Neonatal mortality and morbidity among infants between 24 to 31 complete weeks: a multicenter survey in China from 2013 to 2014 . BMC pediatrics. 2016;16(1):174.

29. Blencowe H, Cousens S, Oestergaard MZ, Chou D, Moller A-B, Narwal R, et al. National, regional, and worldwide estimates of preterm birth rates in the year 2010 with time trends since 1990 for selected 
countries: a systematic analysis and implications. The Lancet. 2012;379(9832):2162-72.

30. Kikuchi K, Okawa S, Zamawe CO, Shibanuma A, Nanishi K, Iwamoto A, et al. Effectiveness of Continuum of Care-Linking Pre-Pregnancy Care and Pregnancy Care to Improve Neonatal and Perinatal Mortality: A Systematic Review and Meta-Analysis. PLoS One. 2016;11(10):e0164965.

31. Brown HK, Speechley KN, Macnab J, Natale R, Campbell MK. Neonatal morbidity associated with late preterm and early term birth: the roles of gestational age and biological determinants of preterm birth. International journal of epidemiology. 2013;43(3):802-14.

32. Nobile S, Marchionni P, Carnielli VP. Neonatal outcome of small for gestational age preterm infants. Eur J Pediatr. 2017;176(8):1083-8.

33. Manuck TA, Rice MM, Bailit JL, Grobman WA, Reddy UM, Wapner RJ, et al. Preterm neonatal morbidity and mortality by gestational age: a contemporary cohort. American Journal of Obstetrics \& Gynecology. 2016;215(1):103. e1-. e14.

34. van Esch JJ, van Heijst AF, de Haan AF, van der Heijden OW. Early-onset preeclampsia is associated with perinatal mortality and severe neonatal morbidity. The Journal of Maternal-Fetal \& Neonatal Medicine. 2017;30(23):2789-94.

35. Schindler T, Koller-Smith L, Lui K, Bajuk B, Bolisetty S. Causes of death in very preterm infants cared for in neonatal intensive care units: a population-based retrospective cohort study. BMC pediatrics. 2017;17(1):59.

36. Kovo M, Schreiber L, Elyashiv O, Ben-Haroush A, Abraham G, Bar J. Pregnancy outcome and placental findings in pregnancies complicated by fetal growth restriction with and without preeclampsia. Reproductive Sciences. 2015;22(3):316-21.

37. Hauth JC, Ewell MG, Levine RJ, Esterlitz JR, Sibai B, Curet LB, et al. Pregnancy outcomes in healthy nulliparas who developed hypertension. Obstetrics \& Gynecology. 2000;95(1):24-8.

38. Selemani, Mwanyangala MA, Mrema S, Shamte A, Kajungu D, Mkopi A, et al. The effect of mother's age and other related factors on neonatal survival associated with first and second birth in rural, Tanzania: evidence from Ifakara health and demographic surveillance system in rural Tanzania. BMC Pregnancy Childbirth. 2014;14:240.

39. Chen F, Bajwa NM, Rimensberger PC, Posfay-Barbe KM, Pfister RE. Thirteen-year mortality and morbidity in preterm infants in Switzerland. Archives of disease in childhood Fetal and neonatal edition. 2016;101(5):F377-83.

40. Modi N, Santhakumaran S, Gray D, Statnikov Y, Battersby C, Ashby D. Survival of very preterm infants admitted to neonatal care in England 2008-2014: time trends and regional variation. 2017. 
41. Weng $Y-H$, Yang $C-Y$, Chiu Y-W. Neonatal outcomes in relation to sex differences: a national cohort survey in Taiwan. Biology of sex differences. 2015;6(1):30.

42. Zisk JL, Genen LH, Kirkby S, Webb D, Greenspan J, Dysart K. Do premature female infants really do better than their male counterparts? American journal of perinatology. 2011;28(3):241-6.

43. Townsel CD, Emmer SF, Campbell WA, Hussain N. Gender Differences in Respiratory Morbidity and Mortality of Preterm Neonates. Frontiers in pediatrics. 2017;5:6.

44. Ito M, Tamura M, Namba F. Role of sex in morbidity and mortality of very premature neonates2017.

45. Ahlsen AK, Spong E, Kafumba N, Kamwendo F, Wolff K. Born too small: who survives in the public hospitals in Lilongwe, Malawi? Archives of disease in childhood Fetal and neonatal edition. 2015;100(2):F150-4.

46. Ballot DE, Chirwa TF, Cooper PA. Determinants of survival in very low birth weight neonates in a public sector hospital in Johannesburg. BMC pediatrics. 2010;10(1):30.

47. Dhaded SMe, Somannavar MS. Neonatal mortality and coverage of essential newborn interventions 2010 - 2013: a prospective, population-based study from low-middle income countries. Reprod Health. 2015;12 Suppl 2:S6.

48. Sheferaw, Teka, yehualaw Z. Survival Analysis of Premature Infants Admitted to Neonatal Int ensive Care Unit (NICU) in Northwest Ethiopia using Semi-Parametric Fr ailty Model. Journal of Biometrics \& Biostatistics. 2015;6(1):1.

\section{Tables}

Table 1: Socio-demographic characteristics of mothers and preterm Neonates at Debretabor General Hospital NICU, Northwest Ethiopia, from January 1, 2014 -December 30,2017 . $(n=535)$ 


\begin{tabular}{lcc}
\hline Characteristics & Frequency & Percentage (\%) \\
\hline Maternal age & 86 & 16.1 \\
$<20$ years & 253 & 47.3 \\
20-29 years & 176 & 32.9 \\
30-39 years & 20 & 3.7 \\
>40 years & & \\
Residence & 146 & 27.3 \\
Urban & 389 & 72.7 \\
Rural & & \\
Sex of neonate & 276 & 51.6 \\
Male & 259 & 48.4 \\
Female & & \\
Neonatal age at admission & & 92.5 \\
0-1days & 495 & 5.6 \\
1-7days & 30 & 1.9 \\
$>7$ days & 10 & \\
\hline
\end{tabular}

Table 2:-Obstetric/gynecological characteristics of mothers who had Preterm neonatal admission at Debretabor General Hospital NICU, Northwest Ethiopia, from January 1, 2014 - December 30, 2017(n=535) 


\begin{tabular}{|c|c|c|c|}
\hline \multirow[t]{3}{*}{ Variables } & Outcome & & Total \\
\hline & Died & Censored & No. (\%) \\
\hline & $\begin{array}{l}\text { No. } \\
(\%)\end{array}$ & \multicolumn{2}{|l|}{$\begin{array}{l}\text { No. } \\
(\%)\end{array}$} \\
\hline \multicolumn{4}{|l|}{ Antenatal care visit } \\
\hline Yes & $125(23.7)$ & $287(53.4)$ & $412(77.1)$ \\
\hline $\begin{array}{l}\text { No } \\
\text { Number of ANC visit }(n=412)\end{array}$ & $42(7.8)$ & $81(15.1)$ & $123(22.9)$ \\
\hline$\geq 4$ visit & $9(2.2)$ & $53(12.9)$ & $62(15.1)$ \\
\hline $\begin{array}{l}<4 \text { visit } \\
\text { Gravidity }\end{array}$ & $116(28.2)$ & 234(56.7) & $350(84.9)$ \\
\hline 1 & $57(10.7)$ & $128(23.9)$ & $185(34.6)$ \\
\hline $2-4$ & $73(13.6)$ & $139(26.0)$ & $212(39.6)$ \\
\hline $\begin{array}{l}\geq 5 \\
\text { Parity }\end{array}$ & $37(6.9)$ & 101(18.8) & $138(25.7)$ \\
\hline First time pregnant & $63(11.8)$ & $148(27.7)$ & $211(39.3)$ \\
\hline 1-4 births & $81(15.1)$ & $161(30.1)$ & $242(45.2)$ \\
\hline $\begin{array}{l}\geq 5 \text { births } \\
\text { Antenatal }\end{array}$ & $23(4.3)$ & $59(11.0)$ & $82(15.3)$ \\
\hline corticosterola $(n=502)$ & $27(5.3)$ & $31(6.2)$ & $58(11.5)$ \\
\hline $\begin{array}{l}\text { No } \\
\text { Place of birth }\end{array}$ & $128(23.3)$ & $316(63.0)$ & $444(88.5)$ \\
\hline Inborn & $97(18.1)$ & $225(42.1)$ & $\begin{array}{l}322 \\
(60.2)\end{array}$ \\
\hline Out born & $70(13.1)$ & 143(26.7) & $213(39.8)$ \\
\hline Pregnancy status & & & \\
\hline Single & $127(23.7)$ & $316(59.1)$ & $443(82.8)$ \\
\hline Twin & $39(7.2)$ & $49(9.2)$ & $88(16.4)$ \\
\hline $\begin{array}{l}\text { Triplet } \\
\text { Maternal complication }\end{array}$ & $1(0.2)$ & $3(0.6)$ & $4(0.8)$ \\
\hline Yes & $76(7.2)$ & $111(20.7)$ & 187(34.9) \\
\hline $\begin{array}{l}\text { No } \\
\text { Maternal complication lists }\end{array}$ & $91(17.0)$ & $257(48.0)$ & $348(65.0)$ \\
\hline Antepartum hemorrhage & $12(2.24)$ & 17(3.2) & $29(5.42)$ \\
\hline
\end{tabular}




$\begin{array}{llll}\text { Chorioamnionitis } & 2(0.4) & 6(1.1) & 8(1.5) \\ \text { Preeclampsia/eclampsia } & 40(7.5) & 44(8.2) & 84(15.7) \\ \text { Cephalopelvic disproportion } & 2(0.4) & 10(1.87) & 12(2.27) \\ \text { Premature rupture of } & 27(5.1) & 32(6.0) & 59(11.1) \\ \text { membrane } & & & 15(1.9) \\ \text { Others* } & 5(0.01) & 10(1.9) & 15\end{array}$

Others*: Cord prolapse, Nonreassurance fetal heart pattern, oligohydramnios, polyhydramnios

Table 3:-Neonatal characteristics of mothers who had Preterm neonatal admission at Debretabor General Hospital NICU, Northwest Ethiopia from January 1, 2014 - December $30,2017(n=535)$ 


\begin{tabular}{|c|c|c|c|}
\hline riable & & & Total \\
\hline & Died & Censored & No. \\
\hline
\end{tabular}

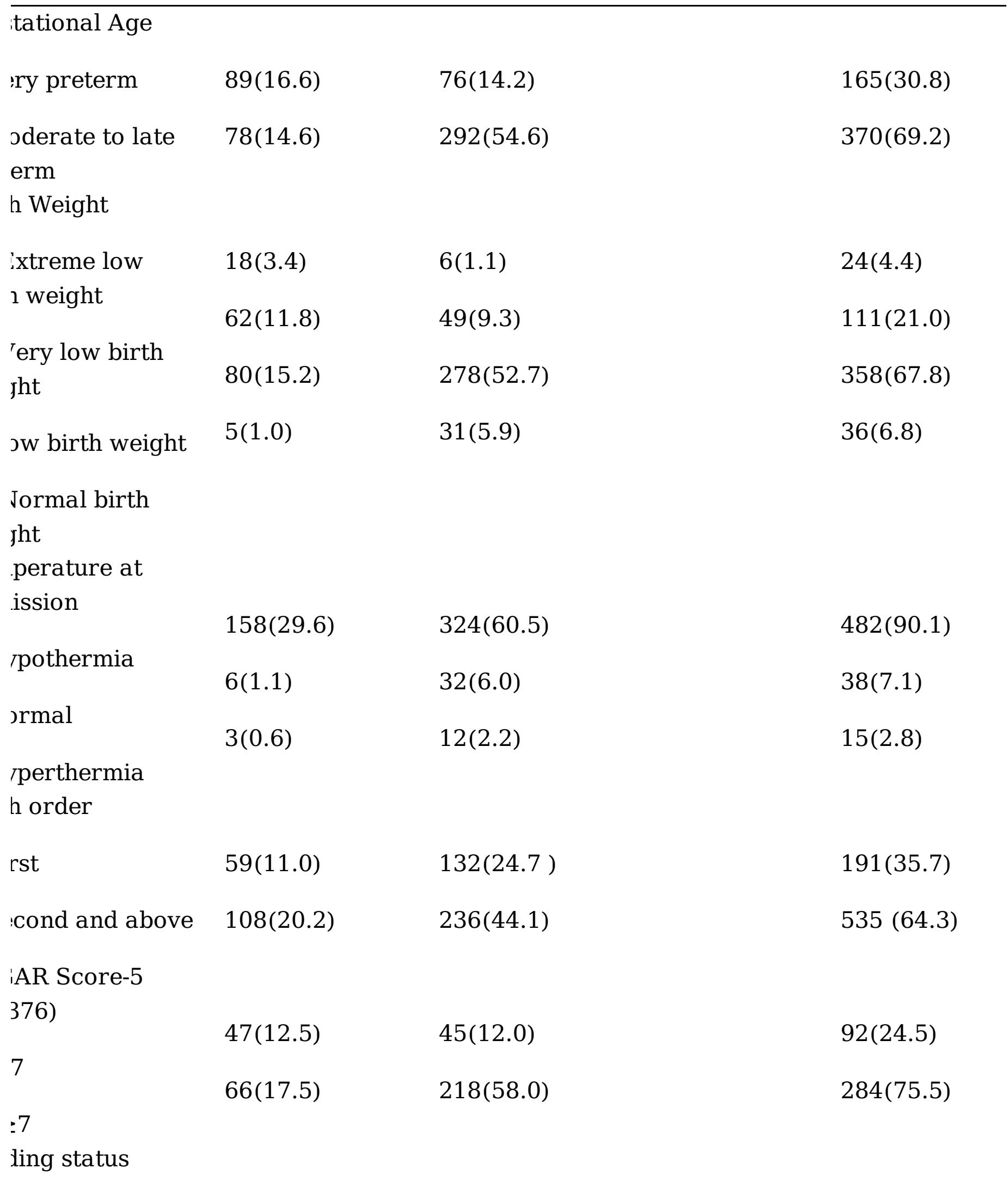




\begin{tabular}{llll} 
ireastfeeding & $47(8.8)$ & $287(53.6)$ & $334(62.4)$ \\
'ormula feeding & $3(0.6)$ & $19(3.6)$ & $22(4.2)$ \\
$\begin{array}{l}\text { Jothing per oral } \\
\text { natal complication at admission }\end{array}$ & $117(21.9)$ & $62(11.5)$ & $179(33.4)$ \\
Yes & $160(30.0)$ & $301(56.3)$ & $461(86.2)$ \\
No & $7(1.3)$ & $67(12.5)$ & $74(13.8)$ \\
$\begin{array}{l}\text { natal } \\
\text { plication list }\end{array}$ & & & \\
jiratory distress & $104(19.4)$ & $108(20.2)$ & $212(39.6)$ \\
$\begin{array}{l}\text { Irome } \\
\text { onium }\end{array}$ & $5(0.9)$ & $15(2.8)$ & $20(3.7)$ \\
ration syndrome & & & $346(64.7)$ \\
sis & $113(21.1)$ & $233(43.8)$ & $97(18.1)$ \\
natal asphyxia & $51(9.5)$ & $46(8.6)$ & $13(2.4)$ \\
nemia & $7(1.3)$ & $6(1.1)$ & $13(2.43)$ \\
undice & $4(0.75)$ & $9(1.68)$ & $18(3.4)$ \\
ongenital & $7(1.3)$ & $11(2.10)$ & $47(8.7)$ \\
:hers** & $18(3.4)$ & $29(5.4)$ & \\
\hline
\end{tabular}

Others**: Hypoglycemia, necrotizing enter colitis, lower leg deformity, Meningitis, Neonatal seizure, Ophthalmic neon trim, Transient tachypnea, Cranocenthesis

Table 4: Cox-proportional hazard model of predictors of mortality of preterm neonates admitted in NICU, Debretabor General Hospital, from January 1, 2014-December 30, $2017(n=535)$ 


\begin{tabular}{lllll}
\hline Variable & Died & Censored & CHR (95\%CI) & AHR (95\%CI) \\
& No. (\%) & No. (\%) & & \\
\hline $\begin{array}{l}\text { Gestational } \\
\text { age }\end{array}$ & & & & \\
$<32$ wks & $78(16.6)$ & $76(14.2)$ & $2.57(1.89,3.49)$ & $1.74(1.24,2.46)^{*}$ \\
& $78(14.6)$ & $292(54.6)$ & 1 & 1
\end{tabular}

Antenatal corticosteroid

Yes

27(5.4)

No

128(25.8)

Maternal complication

Yes

76(7.2)

111(20.7)

257(48.0)

44(8.2)

$324(60.6)$

No

127(23.7)

Premature rupture of membrane

Yes

27(5.0)

$140(26.1)$

No

Sex

Male

98(18.3)

Birth Weight

Extremely
LBW
Very LBW

Low birth

weight
69(12.9)

18(3.4)

62(11.8)

80(15.2)

5(1.0)
178(33.3)

190(35.5)

$32(6.0)$

336(62.8)

6(1.1)

49(9.3)

278(52.7)

31(5.9)
$1.58(1.05,2.40)$

$1.15(0.73,1.83)$

1

1 
Normal birth

weight

APGAR Score-

5

$\begin{array}{lllll} & 47(12.5) & 45(12.0) & 2.15(1.5,3.01) & 1.09(0.64,1.87) \\ \geq 7 & 66(17.5) & 218(58.0) & 1 & 1\end{array}$

Neonatal health problems at admission

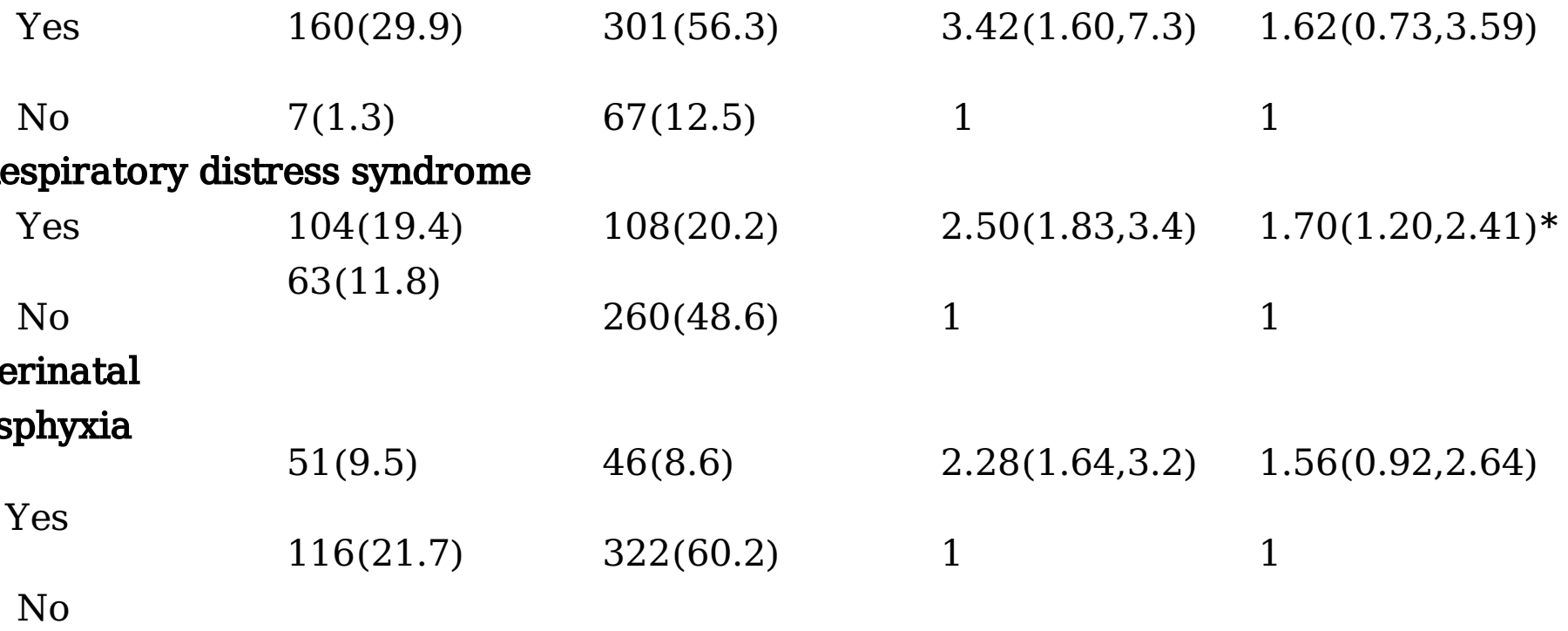

*Significant variable

Figures 


\section{4 preterm neonates admitted}

during the study period

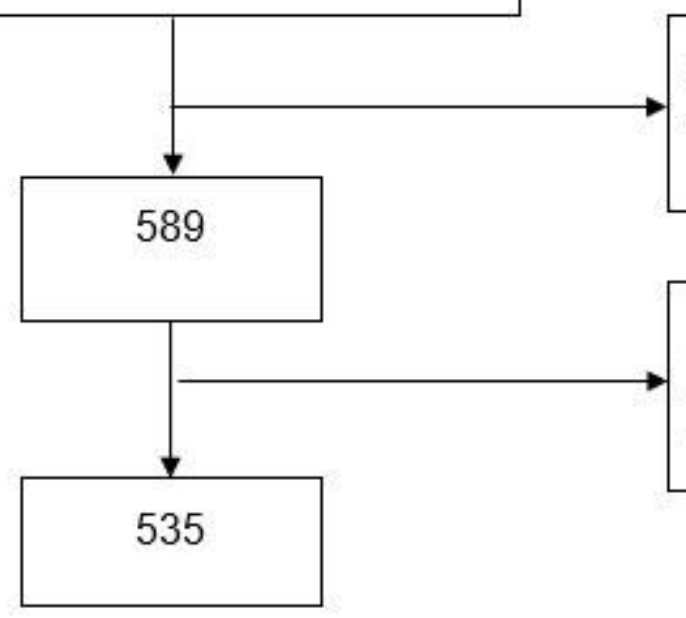

25 charts were not found in the medical chart room

54 excluded due to exclusion criteria, inconsistencies and incompleteness of abstraction sheet

\section{Figure 1}

Study participant selection process in Northwest Ethiopia from January 1, 2014-December 30, 2017

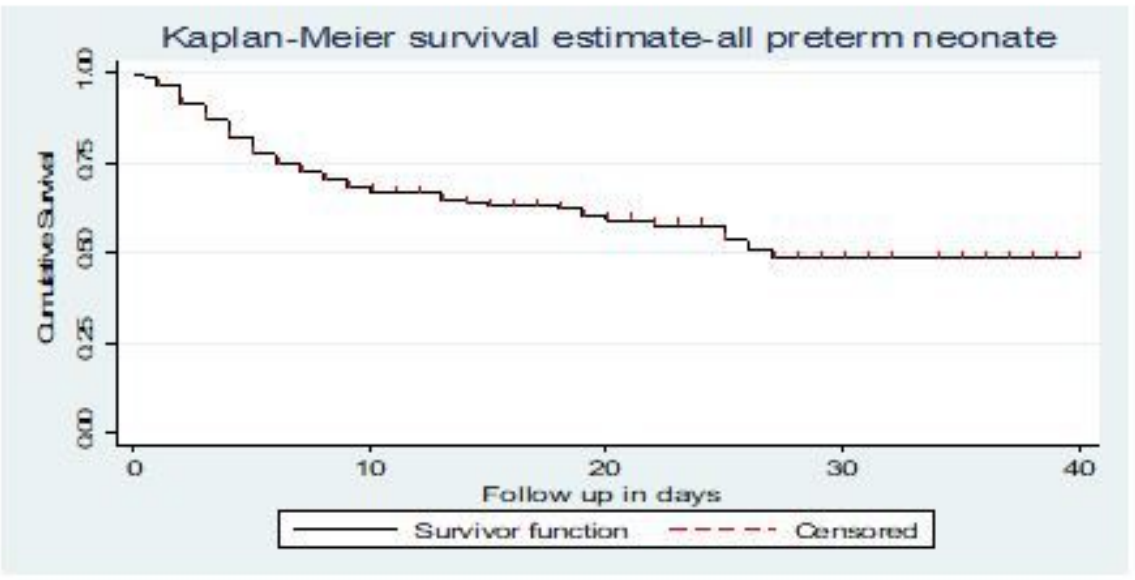

Figure 2

Summary of Kaplan-Meier estimate of survival probability among preterm neonate admitted at Debretabor General Hospital NICU, Northwest Ethiopia, from January 1, 2014-December 30,2017 